\title{
Planning water-energy-food nexus system management under multi-level and uncertainty
}

L. Yu ${ }^{1 *}$, Y. Xiao ${ }^{2}$, X.T. Zeng ${ }^{3}$, Y.P. $\mathrm{Li}^{4}$, Y.R. Fan $^{5}$

$1^{*}$ (Corresponding Author) School of Water Conservancy Engineering, Zhengzhou University, Zhengzhou 450001, China; Zhengzhou Key Laboratory of Water Resource and Environment, Zhengzhou, 450001, China; Henan Key Laboratory of Groundwater Pollution Prevention and Rehabilitation, Zhengzhou, 450001, China; E-mail: yulei2018@zzu.edu.cn

${ }^{2}$ School of Water Conservancy Engineering, Zhengzhou University, Zhengzhou 450001, China; E-mail: xiaoyaocs@163.com

${ }^{3}$ Capital University of Economics and Business, Beijing, 100070, China; E-mail: zxt1231@ sina.com

${ }^{4}$ School of Environment, Beijing Normal University, Beijing 100875, China; E-mail: yongping.li@iseis.org

${ }^{5}$ Department of Civil and Environmental Engineering, Brunel University London, Uxbridge, UB8 3PH, United Kingdom; E-mail: yurui.fan@gmail.com 


\begin{abstract}
In this study, a multi-level interval fuzzy credibility-constrained programming (MIFCP) method is developed for planning the regional-scale water-energy-food nexus (WEFN) system. MIFCP cannot only deal with uncertainties expressed as interval parameters and fuzzy sets, but also handle conflicts and hierarchical relationships among multiple decision departments. The MIFCP approach is then applied to planning the WEFN system of Henan Province, China. Solutions of three different decision targets in various hierarchy levels, five scenarios with different decision makers' objectives and five credibility levels toward different necessity degrees are examined. Several findings in association with various planting structures, water resources demand, energy consumption, fertilizer and pesticide utilizations and system benefits are achieved. Results reveal that the future total irrigation water can decrease by $1.5 \%$ from years 2020 to 2025 . They also disclose that the total cultivated area can change by $1.9 \%$ owing to the variation of fertilizer and pesticide change. Compared to single level programming (SLP) and bi-level programming (BP) approaches, the MIFCP-WEFN model can help decision-makers identify the optimal agricultural water resourceses management schemes by means of the leadership of water resources managers as well as the feedback of two diverse followers (i.e. energy managers and agricultural managers).
\end{abstract}

Keywords: multi-level programming; planning; scenario analysis; uncertainty; water-energy-food nexus system 


\section{Introduction}

\subsection{Motivation}

In the context of rapid global development, guaranteeing stable supply of basic important resources can maintain the development of society (Wostl, 2019) [1]. Acceleration of industrialization development, population growth and economic globalization are associated with massive comsumption of water, energy and food, which will exceed the current global carrying capacity (Steffen et al., 2015) [2]. Such phenomena cannot only be deemed as a general problem

of administration but also come into being a large number of intricacies among water, energy and food (Liu et al., 2015) [3]. On the one hand, food transport, water treatment, farming, irrigation and water supply require energy to sustain, while water resources can ensure stabilized energy generation, normal crops growth, processing and food production; on the other hand, food can also promote the development of virtual water trade and bioenergy (Liu et al., 2015; Shang et al., 2018) $[3,4]$. However, the challenge of ensuring demands of water, food and energy is expanding accompanyed with the urbanization process (Das et al., 2015; Yu et al., 2018) [5, 6]. The deterioration of each factor may spread to other components and cause serious consequences. The policy measure and security of water, energy or food may break the fragile balance among the three resources through critical demand and supply mechanism (Keskinen et al., 2016; Owen et al., 2018) [7, 8]. Therefore, formulating a high-efficiency and optimal allocation of water, energy and food can both coordinate rapid development of various relevant departments and guarantee social stability and harmony (Martinez et al., 2018; Wang et al., 2018) [9, 10].

\subsection{Literature review}

\subsubsection{The nexus of water-energy, water-food and energy-food}

Previously, many research works were conducted to explore management strategies of water-energy nexus (WEN), water-food nexus (WFN) and energy-food nexus (EFN). There are lots of studies based on the WEN and water footprint theory (Perrone et al., 2011; Yu et al., 2019) [11, 12]. For example, Tsolas et al. (2018) [13] and Liu et al. (2019) [14] employed a graphical 
and systematic program with the purpose of identifying and eliminating surplus from consumption and productiom of WEN system. Salmoral and Yan (2018) [15] used the theory of virtual water and embedded energy to explore water and energy allocations in the economic system. Khan et al. (2018) [16] proposed an integrated energy modelling for managing the WEN system. Since agriculture is the largest water user, research on quantifying water-utilization efficiency of agricultural products based on water footprint theory has been widely accepted. For example, Zhang et al. (2019) [17] developed a forward water footprint theory and carried out a new field of virtual water research. Chapagain et al. (2002) [18] analyzed the virtual water flow at the global and national levels from a macro level through coupling virtual water trade and water footprint. However, few studies were focused on food-energy linkages, and the relevant studies could be divided into two major areas: energy consumption during food production and biomass energy in agricultural sector (FAOUN, 2012; Souty et al., 2012; Xydis et al., 2017) [19, 20, 21]. In detail, Georgiou et al. (2018) [22] developed a first-principle model for optimizing the energy configuration in food production processes. Bilandzija et al. (2018) [23] explored the ascertain energy potential from the obtainable crops by seting up multiple scenarios. Although the above studies can effectively handle the conflicts between the two resources, they are incapable of handling the inter-relations among three resources (i.e. water, energy and food). Thus the research on the relationship of water-energy-food nexus (WEFN) becomes one of the research hotspots (Venghaus and Hake, 2018) [24].

\subsubsection{The nexus of water-energy-food}

Currently, many research works were conducted for optimizating WEFN from the perspective of qualitative analysis (Karan and Asadi, 2018; Namany et al., 2019; Zhou et al., 2019) [16, 25, 26]. For example, Karan and Asadi (2018) [16] built a quantitative model to determine contribution of water, energy or food sub-system on the entirety of durative system. Zhou et al. (2019) [26] proposed a systematic method for considering synergy of WEFN system. However, the above researches were based on quantitative description of the relationship among water, energy and food. Actually, there are some uncertain parameters or variables existing in the WEFN system as a result of subjective experience, economy fluctuation and vague observation data (Li et al., 2019; Zeng et al., 2019) [27, 28]. For instance, Hussien et al. (2018) [29] developed a new approach 
based on risk analysis to address the uncertainties related to demand-supply counterpoise and seasonal changes in the WEFN system. Li et al. (2019) [30] integrated multiple objectives and random-boundary interval programing into the WEFN optimization modeling to handle ambiguous parameters related to the undulations of fundamental resources and changements of socio-economic activities. Mercure et al. (2019) [31] handled the impact of global environmental and economic changes by way of four different case studies.

\subsection{Research gap}

Summarily, there are many research works on WEN, WFN and EFN under uncertainty (Perrone et al., 2011; Georgiou et al., 2018; Tsolas et al., 2018; Liu et al., 2019; Yu et al., 2019; Zhang et al., 2018) $[11,22,13,14,32,33]$. Even if the above methods are effective for handling the interactive contradictions between the two related resources while they are invalid to solve the inter-relations among multiple resources (Venghaus and Hake, 2018; Yu et al., 2019) [24, 32]. In addition, the previous studies for managing WEFN system are mainly based on the determinately qualitative analysis, and the inexact optimization approaches associated with the WEFN are limited to the uncertainty analysis from subjective experience, economy fluctuation and system error (Karan and Asadi, 2018; Li et al., 2019; Namany et al., 2019; Zhou et al., 2019) [16, 27, 25, 26]. Actually, there exist hierarchical relationships among multiple decision departments (i.e. water department, energy department and agriculture department), in which the objective of the decision-maker who is prioritized shall be preferably satisfied, then the other decision-makers will change as the priority of decision-makers change (Chen et al., 2017) [34]. Few studies are employed to manage the real-world WEFN issues in a hierarchical order of multiple decision-making departments involving multiple uncertainties caused by subjective experience, economy fluctuation and system error.

\subsection{Contribution}

This paper aims to propose a multi-level interval fuzzy credibility-constrained programming (MIFCP) method through coordinating fuzzy credibility-constrained programming (FCP), multi-level programming (MP) and interval parameter programming (IPP) into one framework. 
MIFCP integrates the unique contribution of each individual technique which can better enhance the method's capability. Compared with the WEN, WFN and EFNsystems, WEFN system can reflect interrelations and contradictions among multiple resouces (Georgiou et al., 2018; Khan et al., 2018; Zhang et al., 2018) [22, 35, 33]. In comparison with research works from Hussien et al. (2018) and Mercure et al. (2019), MIFCP can handle multiple objectives or conflicts in a hierarchical order. Compared to the general multi-objective programming method adopted by $\mathrm{Li}$ et al. (2019) [30], MIFCP has its effectiveness in dealing with hierarchical relationships among various managers and handling uncertainties expressed as interval parameters, fuzzy sets and modeled scenarios. Summarily, MIFCP has its significant contributions for management of WEFN system: (a) it can effectively handle the conflicts and hierarchical relationships among multiple decision departments (i.e. water department, energy department and agricultural department); (b) it can simultaneously take the hierarchical order of multiple decision-making departments, as well as multiple uncertainties caused by subjective experience, economy fluctuation and system error into account.

Then, a MIFCP-WEFN model is developed for planning the WEFN system of Henan Province, China, in which three decision targets (i.e. system benefit, water resources utilization and energy consumption) are included. In detail, the water resource sector focuses on the minimization of irrigated water consumption, the energy sector purses the minimization of energy consumption, and the agricultural sector aims at achieving the maximization of system benefit. Besides, five scenarios with different decision makers' objectives and five $\alpha$ levels corresponding to different necessity degrees are also considered. Moreover, based on the comparative analyses, the superiority of MIFCP compared to other inexact optimization methods, and the accuracy of the results between MIFCP-WEFN model and actual situation, will be validated to demonstrate the effectiveness of the study. Results will help decision makers: (a) address multiple conflicts and multi-uncertainty of WEFN system in a hierarchical order; (b) discern optimal WEFN schemes among system benefit, water resources utilization, energy consumption, environmental mitigation and land use; (c) provide decision supports for managing water, energy and food in a water-safely, food-reliably and energy-efficiently way.

\subsection{Objective}


The main objective of this study is to propose a MIFCP method for configuring the water, energy and food resources in a hierarchical order under uncertainty. The MIFCP-WEFN model is developed for a complex interrelated network connected by multiple decision-makers, multiple components and multiple uncertainties, as described in Figure 1. The surplus of the article can be dissected into five parts: Section 2 proposes the formulation and solution process of MIFCP; Section 3 introduces the basic situation of Henan Province and illustrates development of MIFCP-WEFN model; Section 4 describes the results by the application of MIFCP method; Section 5 gives the discussions of superiority and accuracy validation; Section 6 depicts the main conclusions and extensions.

\section{Methodology}

Decision maker is responsible for allocating agricultural water resources within a maximum system benefit. Energy and food resources, as the two supporting elements for the sustainable agricultural water resources management, cannot only consume a large amount of water resources but also affect the transfer of virtual water. Multi-level programming (MP) is effective for dealing with hierarchical relationships among multiple decision managers in a hierarchical order. A general MP model can be described as:

$$
\operatorname{Min}_{x_{1}} F_{U}\left(x_{1}, x_{2}, x_{3}\right)
$$

where $x_{2}$ solves:

$$
\operatorname{Min}_{x_{2}} F_{M}\left(x_{1}, x_{2}, x_{3}\right)
$$

where $x_{3}$ solves:

$$
\operatorname{Min}_{x_{3}} F_{L}\left(x_{1}, x_{2}, x_{3}\right)
$$

subject to:

$$
G=\left\{\left(x_{1}, x_{2}, x_{3}\right) \mid \mathrm{g}_{i}\left(x_{1}, x_{2}, x_{3}\right) \leq 0, i=1,2, \mathrm{~K}, \mathrm{~m}, x_{1}, x_{2}, x_{3} \geq 0\right\}
$$

where $x_{1} \in R^{n 1}, \quad x_{2} \in R^{n 2}$ and $x_{3} \in R^{n 3}$. These variables are divided into multiple levels: 
upper-level $\left(x_{1} \in R^{n 1}\right)$, middle-level $\left(x_{2} \in R^{n 2}\right)$, and lower-level $\left(x_{3} \in R^{n 3}\right)$ variables; the $F_{U}: R^{n 1} \times R^{n 2} \times R^{n 3} \rightarrow R, \quad F_{M}: R^{n 1} \times R^{n 2} \times R^{n 3} \rightarrow R$, and $F_{L}: R^{n 1} \times R^{n 2} \times R^{n 3} \rightarrow R$ are upper-, middle-, and lower-level objective functions; $G$ is the multi-level restricted group. In the MP model, upper-level decision maker (UDM), middle-level decision maker (MDM), and lower-level decision maker (LDM) follow the coordination and feedback of Stackelberg game (Emam, 2006) [36].

Although MP can efficiently address contradictions among different decision makers (e.g., agricultural, energy and water) at different decision-making levels, it is incapable of handling uncertain system coefficients such as the fluctuated crop and seed price, dynamic water resources consumption. In real-world agricultural water resources management, some system coefficients (e.g., fertilizer and pesticide utilization) and constraint conditions need to be estimated. Fuzzy credibility-constrained programming (FCP) approach devised by Liu and Liu (2002) [37] has been frequently applied to handle ambiguous system parameters by using fuzzy set theory (Zeng et al., 2014; Li et al., 2015; Veiseh et al., 2018) [38, 39, 40]. Moreover, some economic parameters are affected by the socio-economic, political and technical factors, which can hardly be quantified as fuzzy sets but can be presented as interval values through using the interval parameter programming (IPP) technique (Nie et al., 2016; Yu et al., 2018) [41, 42]. By integrating IPP into FCP, an interval fuzzy credibility-constrained programming (IFCP) can be described as:

$$
\operatorname{Max} f^{ \pm}=\sum_{j=1}^{n} c_{j}^{ \pm} x_{j}^{ \pm}
$$

subject to:

$$
\operatorname{Cr}\left\{\sum_{j=1}^{n} a_{j}^{ \pm} x_{j}^{ \pm} \leq b^{\natural}\right\} \geq \alpha_{i}, x_{j}^{ \pm} \geq 0
$$

where $b^{\text {th }}$ is fuzzy coefficient with fuzzy-interval membership function, $b^{\natural}=\left(b_{1}^{ \pm}, b_{2}^{ \pm}, b_{3}^{ \pm}\right)=\left\{\left[b_{1}^{-}, b_{1}^{+}\right],\left[b_{2}^{-}, b_{2}^{+}\right],\left[b_{3}^{-}, b_{3}^{+}\right]\right\}$and $a_{j}^{ \pm}$are interval coefficients with upper and lower bounds, $a_{j}^{ \pm}=\left[a_{j}^{-}, a_{j}^{+}\right]$. Equation $(2 \mathrm{~b})$ can be transferred as follows: 


$$
\operatorname{Cr}\left\{\sum_{j=1}^{n} a_{j}^{ \pm} x_{j} \leq b^{\Phi}\right\}= \begin{cases}1 & \text { if } \sum_{j=1}^{n} a_{j}^{ \pm} x_{j} \leq b_{1}^{ \pm} \\ \frac{2 b_{2}^{ \pm}-b_{1}^{ \pm}-\sum_{j=1}^{n} a_{j}^{ \pm} x_{j}}{2\left(b_{2}^{ \pm}-b_{1}^{ \pm}\right)} & \text {if } b_{1}^{ \pm} \leq \sum_{j=1}^{n} a_{j}^{ \pm} x_{j} \leq b_{2}^{ \pm} \\ \frac{\sum_{j=1}^{n} a_{j}^{ \pm} x_{j}-b_{3}^{ \pm}}{2\left(b_{3}^{ \pm}-b_{2}^{ \pm}\right)} & \text {, if } b_{2}^{ \pm} \leq \sum_{j=1}^{n} a_{j}^{ \pm} x_{j} \leq b_{3}^{ \pm} \\ 0 & \text {, if } b_{3}^{ \pm} \leq \sum_{j=1}^{n} a_{j}^{ \pm} x_{j}\end{cases}
$$

Generally, the significant credibility level $\lambda$ should be greater than 0.5 . Thus, for each $0.5 \leq \alpha \leq 1$, we have:

$$
\operatorname{Cr}\left\{\sum_{j=1}^{n} a_{j}^{ \pm} x_{j} \leq b^{\natural}\right\}=\frac{2 b_{2}^{ \pm}-b_{1}^{ \pm}-\sum_{j=1}^{n} a_{j}^{ \pm} x_{j}}{2\left(b_{2}^{ \pm}-b_{1}^{ \pm}\right)} \geq \alpha
$$

Then,

$$
\sum_{j=1}^{n} a_{j}^{ \pm} x_{j} \leq b_{2}^{ \pm}+(1-2 \lambda)\left(b_{2}^{ \pm}-b_{1}^{ \pm}\right)
$$

Integrating MP into IFCP, a multi-level interval fuzzy credibility-constrained programming (MIFCP) method can be developed as:

Upper level:

$$
\operatorname{Min}_{x_{1}^{ \pm}} F_{U}^{ \pm}\left(x_{1}^{ \pm}, x_{2}^{ \pm}, x_{3}^{ \pm}\right)
$$

Middle level:

$$
\operatorname{Min}_{x_{2}^{ \pm}} F_{M}^{ \pm}\left(x_{1}^{ \pm}, x_{2}^{ \pm}, x_{3}^{ \pm}\right)
$$

where $x_{3}^{ \pm}$solves:

$$
\operatorname{Min}_{x_{3}^{ \pm}} F_{L}^{ \pm}\left(x_{1}^{ \pm}, x_{2}^{ \pm}, x_{3}^{ \pm}\right)
$$


subject to:

$$
G^{ \pm}=\left\{\left(x_{1}^{ \pm}, x_{2}^{ \pm}, x_{3}^{ \pm}\right) \mid C r\left[A_{i}^{ \pm}(t) X^{ \pm}<b_{i}^{ \pm}(t)\right]>\alpha_{i}, i=1,2, \mathrm{~K}, \mathrm{~m}, x_{1}^{ \pm}, x_{2}^{ \pm}, x_{3}^{ \pm} \geq 0, \alpha_{i} \in[0,1]\right\}
$$

By discriminating the relationship between coefficient and variables, and the relationship between objective function and constraints, an interactive algorithm is put forward to solve the model (3) (Lv et al.,2010) [43]. Therefore, the model (3) can be described as:

$$
\begin{aligned}
& \operatorname{Min}_{x_{1}^{ \pm}} F_{U}^{ \pm}\left(x_{1}^{ \pm}, x_{2}^{ \pm}, x_{3}^{ \pm}\right) \\
& \operatorname{Min}_{x_{2}^{ \pm}} F_{M}^{ \pm}\left(x_{1}^{ \pm}, x_{2}^{ \pm}, x_{3}^{ \pm}\right) \\
& \operatorname{Min}_{x_{3}^{ \pm}} F_{L}^{ \pm}\left(x_{1}^{ \pm}, x_{2}^{ \pm}, x_{3}^{ \pm}\right)
\end{aligned}
$$

subject to:

$$
G^{ \pm}=\left\{\left(x_{1}^{ \pm}, x_{2}^{ \pm}, x_{3}^{ \pm}\right) \mid C r\left[A_{i}^{ \pm}(t) X^{ \pm}<b_{i}^{ \pm}(t)\right]>\alpha_{i}, i=1,2, \mathrm{~K}, \mathrm{~m}, x_{1}^{ \pm}, x_{2}^{ \pm}, x_{3}^{ \pm} \geq 0, \alpha_{i} \in[0,1]\right\}
$$

\section{Application}

Henan Province $\left(110^{\circ} 21^{\prime}-116^{\circ} 39^{\prime} \mathrm{E}, 31^{\circ} 23^{\prime}-36^{\circ} 22^{\prime} \mathrm{N}\right)$ is located in the middle and lower reaches of the Yellow River in the south of the North China Plain, covering an area of $167,000 \mathrm{~km}^{2}$. In recent years, Henan province has been deemed as the farm production basis and the economic and wealth center of the Central Plains (Wang and Zhang, 2013) [44]. The number of workers, scholars and residents has risen in a straight line due to pursuing more entrepreneurial and job opportunities in the study area. At the beginning of 2018, the population living in Henan Province has reached 90.5 million with an average annual growth rate of 6.15\% (SBHM, 2017; HPPG, 2017) [45, 46]. Similarly, the problems of energy shortage and environmental pollution become increasingly prominent (Wang et al., 2016) [47]. As an important guarantee for enhancing the people's living standard and stable economic development, agriculture should be paid more attention (Ma and Li, 2010; Cai et al., 2019) [48, 49]. Therefore, upgrading agricultural planning structure and improving agricultural production capacity, which can handle the food safety and demand caused by population growth, is an extremely urgent issue (Zhang et al., 2018) [33]. 
For a real-world WEFN system, there are multiple components, multiple sectors and multiple uncertainties associated with various decision makers. The management of WEFN system not only considers the profit of the entire system but also balances contradictions among agricultural, water and energy resources sectors according to different decision-making priorities. Besides, agricultural activities are subjected to some factors (e.g. market price fluctuations, dynamic demand-supply balance and subjective experience), which can lead to some system errors. Based on the MIFCP method, a MIFCP-WEFN model is established for planning the WEFN system of Henan province, China. In the MIFCP-WEFN model, some agricultural activities (i.e. crop cultivation, crop processing, food production, food transportation) in association with some constraint limitations (i.e. fertilizer utilization, pesticide utilization, energy consumption for farming, water consumption for irrigation) are considered. Three decision targets (i.e. system benefit, water resources utilization and energy consumption) are selected. As depicted in Figure 1, the MIFCP-WEFN model covers three decision makers: the UDM hammers at irrigation water management; the MDM concentrates on energy allocation for agricultural activities; the LDM is limited by the agriculture department that pay more consideration to accomplishing a maximized system benefit.

Place Figure 1 here

The target of LDM is to maximize the system benefit of agricultural production subjected to a series of constraints. The system benefit involves many agriculture-related activities which cover the revenues for agricultural products, costs for fertilizer, irrigation, pesticide, films, seeds and energy consumption (Tang et al., 2019) [50]. The low-level objective is:

$$
\operatorname{Max} f_{1}^{ \pm}=(1)-[(2)+(3)+(4)+(5)+(6)+(7)]
$$

(1) Revenues for agricultural products, which consist of the unit price of major farm products $\left(\mathrm{OMP}_{t, v}^{ \pm}\right)$and the output of major farm products $\left(\mathrm{OMFP}_{t, v}^{ \pm}\right)$: 


$$
\sum_{t=1}^{6} \sum_{v=1}^{9} S A F_{t, v}^{ \pm} \times \operatorname{OMFP}_{t, v}^{ \pm} \times O M P_{t, v}^{ \pm}
$$

(2) Costs for irrigation water, which consist of the effective utilization factor of irrigation water $(\eta)$, the agricultural water quota of each crop $\left(A W Q_{t, v}^{ \pm}\right)$and the irrigation water price (WP $\left.P_{t}^{ \pm}\right)$:

$$
\sum_{t=1}^{6} \sum_{v=1}^{9} S A F_{t, v}^{ \pm} \times \eta \times A W Q_{t, v}^{ \pm} \times W P_{t}^{ \pm}
$$

(3) Costs for fertilizers, which consist of the effective use coefficient of chemical fertilizer ( $\theta)$, the consumption of chemical fertilizer for each crop $\left(C C F A_{t, v}^{ \pm}\right)$and the unit price of chemical fertilizer $\left(\mathrm{CFP}_{t}^{ \pm}\right)$:

$$
\sum_{t=1}^{6} \sum_{v=1}^{9} S A F_{t, v}^{ \pm} \times \theta \times C C F A_{t, v}^{ \pm} \times C F P_{t}^{ \pm}
$$

(4) Costs for pesticides, which consist of the spraying pesticide effective utilization factor $(\vartheta)$, the consumption of pesticides for each crop $\left(C C P A_{t, v}^{ \pm}\right)$and the unit price of pesticides $\left(E C P_{t}^{ \pm}\right)$:

$$
\sum_{t=1}^{6} \sum_{v=1}^{9} S A F_{t, v}^{ \pm} \times \vartheta \times C C P A_{t, v}^{ \pm} \times E C P_{t}^{ \pm}
$$

(5) Costs for agricultural films, which consist of the unit price of plastic film use for agriculture $\left(\mathrm{PFAP}_{t}^{ \pm}\right)$:

$$
\sum_{t=1}^{6} \sum_{v=1}^{9} S A F_{t, v}^{ \pm} \times P F A P_{t}^{ \pm}
$$

(6) Costs for electricity consumption of agricultural machinery, which consist of the effective utilization factor of energy $(\varphi)$, the unit price of plastic film use for agriculture (PAM $\left.{ }_{t}^{ \pm}\right)$and the unit price of power of agricultural machinery $\left(\mathrm{EP}_{t}^{ \pm}\right)$:

$$
\sum_{t=1}^{6} \sum_{v=1}^{9} S A F_{t, v}^{ \pm} \times \varphi \times P A M_{t}^{ \pm} \times E P_{t}^{ \pm}
$$

(7) Costs for seeds, which consist of the unit price of crop seed ( $\left.S E D P_{t, v}^{ \pm}\right)$:

$$
\sum_{t=1}^{6} \sum_{v=1}^{9} S A F_{t, v}^{ \pm} \times S E D P_{t, v}^{ \pm}
$$

The objective of MDM is to minimize the energy consumption for agriculture activities, including the average energy consumption per $\mathrm{km}^{2}\left(P A M_{t}^{ \pm}\right)$and generalized utilization efficiency $(\varphi)$ for agriculture activities involving transmission and conversion loss:

$$
\operatorname{Min} P A M_{2}^{ \pm}=\sum_{t=1}^{6} \sum_{v=1}^{9} S A F_{t, v}^{ \pm} \times \varphi \times P A M_{t}^{ \pm}
$$




$$
f_{2}^{ \pm}=(1)-[(2)+(3)+(4)+(5)+(6)+(7)]
$$

The objective of UDM is to minimize the irrigation water for agriculture activities, including the agricultural water quota of each crop $\left(A W Q_{t, v}^{ \pm}\right)$and the effective utilization factor of irrigation water $(\eta)$ covering the loss of intake, transfer and delivery:

$$
\begin{aligned}
& \text { Min } I T W_{3}^{ \pm}=\sum_{t=1}^{6} \sum_{v=1}^{9} S A F_{t, v}^{ \pm} \times A W Q_{t, v}^{ \pm} \times \eta \\
& f_{3}^{ \pm}=(1)-[(2)+(3)+(4)+(5)+(6)+(7)]
\end{aligned}
$$

The constraints of WEFN system include the aspects of water, energy, food, land, and environment.

(1) Land use constraint: the distributed land of each crop in the planning horizon should be less than the net cultivable area of claim $\left(S A F_{t, v}^{\max }\right)$ but should be larger than the basic food production $\left(S A F_{t, v}^{\min \pm}\right)$.

$$
\begin{aligned}
& S A F_{t, v}^{\min \pm} \leq S A F_{t, v}^{ \pm} \\
& S A F_{t, v}^{\max \pm} \geq S A F_{t, v}^{ \pm}
\end{aligned}
$$

(2) Irrigation guarantee constraint: The total irrigation water for ensuring the normal growth of all crops must not exceed the claim water availability, which covers the agricultural water quota of each crop $\left(A W Q_{t, v}^{ \pm}\right)$and the effective utilization factor of irrigation water $(\eta)$.

$$
\sum_{v=1}^{9} S A F_{t, v}^{ \pm} \times A W Q_{t, v}^{ \pm} \times \eta \leq I W S_{t}^{ \pm}
$$

(3) Fertilizer environment constraint: The spreading chemical fertilizers covering the consumption of chemical fertilizer for each crop $\left(C C F A_{t, v}^{ \pm}\right)$and the effective use coefficient of chemical fertilizer $(\theta)$ will cause nitrogen and phosphorus pollution, which should be controlled within the standard range $\left(T C \tilde{F}_{t}^{ \pm}\right)$. Such constraint is set as a fuzzy inequality to express decision makers' subjectivity and satisfaction. 


$$
\begin{aligned}
& C r\left\{\sum_{v=1}^{9} S A F_{t, v}^{ \pm} \times C C F A_{t, v}^{ \pm} \times \theta \leq T C \tilde{F}_{t}^{ \pm}\right\} \geq \alpha^{ \pm} \\
& \sum_{v=1}^{9} S A F_{t, v}^{ \pm} \times C C F A_{t, v}^{ \pm} \times \theta \leq T C F_{t}^{ \pm}+\left(1-2 \alpha^{ \pm}\right)\left(T C F_{t}^{ \pm}-T C \underline{F}_{t}^{ \pm}\right)
\end{aligned}
$$

(4) Pesticide environment constraint: The spraying pesticides covering the consumption of pesticides for each crop $\left(C C P A_{t, v}^{ \pm}\right)$and the spraying pesticide effective utilization factor $(\vartheta)$ will bring about COD and eutrophication environmental pollution, which must not exceed the allowable value $\left(T E \tilde{C}_{t}^{ \pm}\right)$. Such constraint related to crop yield and growth is set as a fuzzy inequality to illustrate decision makers' subjectivity and satisfaction.

$$
\begin{aligned}
& C r\left\{\sum_{v=1}^{9} S A F_{t, v}^{ \pm} \times C C P A_{t, v}^{ \pm} \times \vartheta \leq T E \tilde{C}_{t}^{ \pm}\right\} \geq \alpha^{ \pm} \\
& \sum_{v=1}^{9} S A F_{t, v}^{ \pm} \times C C P A_{t, v}^{ \pm} \times \vartheta \leq T E C_{t}^{ \pm}+\left(1-2 \alpha^{ \pm}\right)\left(T E C_{t}^{ \pm}-T E \underline{C}_{t}^{ \pm}\right)
\end{aligned}
$$

(5) Food security constraint: Guarantee the stable supply and demand of local food and the normal life of the people, which are considered according to local basic food requirement $\left(F D_{t, v}^{ \pm}\right)$ and social population.

$$
S A F_{t, v}^{ \pm} \times O M F P_{t, v}^{ \pm}+P A J_{t, v}^{ \pm} \geq F D_{t, v}^{ \pm}
$$

(6) Energy security constraint: The total energy consumption involving the power of agricultural machinery ( $\left.P A M_{t}^{ \pm}\right)$must be kept below the energy allocated to the agricultural department $\left(P A M E_{t}^{ \pm}\right)$.

$$
\sum_{v=1}^{9} S A F_{t, v}^{ \pm} \times P A M_{t}^{ \pm} \leq P A M E_{t}^{ \pm}
$$

(7) Total Area of agricultural constraint: The total cultivable area of all crops must be not exceed the maximum available cultivable area $\left(T T S A F_{t}^{ \pm}\right)$.

$$
\sum_{v=1}^{9} S A F_{t, v}^{ \pm} \leq T T S A F_{t}^{ \pm}
$$

(8) Agricultural films environment constraint: The utilization of agricultural films covering the unit consumption of agricultural film $\left(C A F_{t, v}^{ \pm}\right)$will cause plastic environmental pollution, which must be lower than the allowable value $\left(T E A F_{t}^{ \pm}\right)$.

$$
\sum_{v=1}^{9} S A F_{t, v}^{ \pm} \times C A F_{t, v}^{ \pm} \leq T E A F_{t}^{ \pm}
$$

(9) The constraint of Energy for agricultural machinery security constraint: The mechanical power to supply agricultural farming activities (i.e. sown, harvest, transport and process) must be 
controlled within the available total power of agriculture machinery $\left(E A A M_{t}^{ \pm}\right)$.

$$
\left(\sum_{v=1}^{9} S A F_{t, v}^{ \pm}\right) \times U A M_{t}^{ \pm} \leq E A A M_{t}^{ \pm}
$$

(10) The constraint of energy availability in agricultural irrigation activities: The mechanical power to guarantee the supply of irrigation water (i.e. pumping, transfer and delivery) should be lower than the power availability $\left(E A W_{t}^{ \pm}\right)$.

$$
\sum_{v=1}^{9} E W W_{t, v}^{ \pm} \leq E A W_{t}^{ \pm}
$$

(11) Nonnegative constraint: The decision variables in the solution process should be positive, eliminating infeasibilities while calculating the solution.

$$
S A F_{t, v}^{ \pm} \geq 0
$$

The model's decision variables are the sown area of farm crops under different planning periods $\left(S A F_{t, v}^{ \pm}\right)$. In this study, the leader-follower-interactive solution algorithm will be applied for solving this MIFCP-WEFN problem, in which the resulting linear programming model with crisp parameters will be solved through the simplex algorithm (Dantzig, 1955; Cottle and Dantzig, 1970; Dantzig, 1982) [51, 52, 53]. The concept of satisfactory degree would be used to measure what extent the objective reaches its optima and the constraints were satisfied. The leader can achieve a satisfactory solution by adjusting the followers' limits of satisfactory degrees, and then an overall satisfactory balance among the three levels was obtained (He et al., 2018) [54].

The nomenclature of other parameters and variables are shown as follows. Superscript " \pm " means the interval value with lower and upper bounds; superscript “ $\sim$ "means fuzzy sets; $t$ presents planning periods, $\mathrm{t}=1-6$ are from 2020 to 2025; $v$ presents crop types, $\mathrm{v}=1-9$ are rice, wheat, corn, beans, tuber, oil-bearing crops, cotton, vegetables and fruits, respectively; $f^{ \pm}$is the system benefit of the entire planning horizon $\left(10^{9} \mathrm{RMB} ¥\right) ; \quad \eta$ is the effective utilization factor of irrigation water; $\varphi$ is the effective utilization factor of energy; $\theta$ is the effective utilization coefficient of chemical fertilizer; $\vartheta$ is the spraying pesticide effective utilization factor; $A W Q_{t, v}^{ \pm}$is the agricultural water quota of each crop $\left(\mathrm{m}^{3} / \mathrm{km}^{2}\right) ; C A F_{t, v}^{ \pm}$is the unit consumption of agricultural film $\left(\mathrm{kg} / \mathrm{km}^{2}\right) ; C C F A_{t, v}^{ \pm}$is the consumption of chemical fertilizer 
for each crop $\left(\mathrm{kg} / \mathrm{km}^{2}\right) ; C C P A_{t, v}^{ \pm}$is the consumption of pesticides for each crop $\left(\mathrm{kg} / \mathrm{km}^{2}\right)$; $C F P_{t}^{ \pm}$is the unit price of chemical fertilizer (RMB ¥/kg); $E C P_{t}^{ \pm}$is the unit price of pesticides $(\mathrm{RMB} ¥ / \mathrm{kg}) ; E P_{t}^{ \pm}$is the unit price of power for agricultural machinery (RMB $¥ / \mathrm{KWh}$ ); $E A W_{t}^{ \pm}$is the maximum allowable total power for irrigation collection and delivery (KWh); $E W W_{t, v}^{ \pm}$is the power for irrigation collection and delivery $(\mathrm{KWh}) ; E A A M_{t}^{ \pm}$is the maximum allowable total power for agricultural machinery security $(\mathrm{KWh}) ; F D_{t, v}^{ \pm}$is the food demand for each crop $(\mathrm{kg}) ; I T W^{ \pm}$is the total agricultural irrigation-water consumption $\left(\mathrm{m}^{3}\right) ; I W S_{t}^{ \pm}$is the maximum allowable total agricultural irrigation-water consumption $\left(\mathrm{m}^{3}\right) ; O \operatorname{OMFP}_{t, v}^{ \pm}$is the output of major farm products $\left(\mathrm{kg} / \mathrm{km}^{2}\right) ; O M P_{t, v}^{ \pm}$is the unit price of major farm products (RMB $¥ / \mathrm{kg}$ ); $P F A P_{t}^{ \pm}$is the unit price of plastic film use for agriculture $\left(\mathrm{RMB} ¥ / \mathrm{km}^{2}\right) ; P A M_{t}^{ \pm}$is the power of agricultural machinery $\left(\mathrm{KWh} / \mathrm{km}^{2}\right) ; P A M E_{t}^{ \pm}$is the the maximum allowable total power $(\mathrm{KWh}) ; P A J_{t, v}^{ \pm}$is the purchased crops $(\mathrm{kg}) ; S A F_{t, v}^{ \pm}$is the sown area of farm crops $\left(\mathrm{km}^{2}\right)$; $S A F_{t, v}^{\min \pm}$ is the minimum area of farm crops $\left(\mathrm{km}^{2}\right) ; S A F_{t, v}^{\max \pm}$ is the the maximum area of farm crops $\left(\mathrm{km}^{2}\right) ; S E D P_{t, v}^{ \pm}$is the unit price of crop seed $\left(\mathrm{RMB} ¥ / \mathrm{km}^{2}\right) ; T C F_{t}^{ \pm}$is the total limited consumption of chemical fertilizer $(\mathrm{kg}) ; T E C_{t}^{ \pm}$is the total limited consumption of pesticides $(\mathrm{kg}) ; T_{T S A F_{t}^{ \pm}}$is the maximum allowable total area of agriculture $\left(\mathrm{km}^{2}\right) ; T E A F_{t}^{ \pm}$is the total limited consumption of agricultural films (kg);UAM ${ }_{t}^{ \pm}$is the unit power for agricultural machinery security $\left(\mathrm{KWh} / \mathrm{km}^{2}\right) ; W P_{t}^{ \pm}$is the irrigation water price $\left(\mathrm{RMB} ¥ / \mathrm{m}^{3}\right)$.

The detailed nomenclature for abbreviation is depicted in Appendix A. In this paper, the interrelated crop yield, electricity and water resources consumption of agriculture, as well as economic parameters were collected from the statistical yearbook of Henan province (SBHM, 2017) [45]. The demand and supply of energy, water and food resources were obtained from the Thirteenth Five-Year Plan (i.e. 2016-2020) of Henan Province (HPPG, 2017) [46]. The other coefficients were discovered from the related published papers (Veiseh et al., 2018; Li et al., 2019a, 2019b; Zeng et al., 2019) [40, 30, 39, 28]. As shown in Table 1, five scenarios were 
considered: scenario 1 (S1) takes the maximum system benefit of agriculture as the target of the LDM; scenario 2 (S2) and scenario 3 (S3) set up the minimum water consumption and the minimum energy consumption in agriculture as objectives of the UDM and MDM, respectively; scenario 4 (S4) aims at achieving the maximum satisfactory degree between S1 and S2; scenario 5 (S5) aims to obtain the maximum satisfactory degree among S1, S2 and S3.

Place Table 1 here

The planning horizon was six years corresponding to years 2020-2025. In addition, five credibility levels (i.e. $\alpha=1.0,0.9,0.8,0.7,0.6)$ were also examined. Table 2 shows the crop-related parameters, such as agricultural water quotas, cost of crops, cost of seeds, pesticide and fertilizer demand of crops. Tables 3 and 4 illustrate the sown area of farm crops and crop yield of each crop, respectively. Apart from the above, the total water consumption for agricultural irrigation was acquired from the Water Resources Department of Henan Province (WRDHP, 2017) [55]. In addition, water consumption for each crop was obtained from the Agricultural Basic Water Quota of Henan Province (HBQTS, 2014) [56].

Place Tables 2-4 here

\section{Result Analysis}

\subsection{Crop land allocation}

Figure 2 presents the cultivated area of various crops under five scenarios and six periods. Generally, a decrease in the cultivated area of rice, corn, bean, tuber, and cotton would be found along with the planning periods, whereas the cultivated area of wheat, oil-bearing crops, vegetables, and fruits would increase with time. For example, as shown in Figure 2a, over the planning horizon under $\mathrm{S} 1$, the cultivated area of rice would decrease $369 \mathrm{~km}^{2}$ while the cultivated area of vegetables would increase $348 \mathrm{~km}^{2}$, respectively. This is because the profit and 
cost of different crops would change with periods, which would also be controlled by demanding side from the masses. The above outcomes indicated that the decision makers would need to modify the planting strategy according to the local soil fertility, climatic conditions, agricultural subsidy policy, as well as irrigation infrastructure. In addition, the cultivated area of high-yield fertilizers and pesticides would decrease due to the limitation of environmental pollution capacity. While in contrast, there would be a significant increase in the cultivated area of crops, which would bring about more profit and result in resource scarcity at the same time. Figure $2 \mathrm{~h}$ illustrates that the cultivated area of vegetables in period 1 under $\mathrm{S} 1$ and $\mathrm{S} 2$ would be $16,470 \mathrm{~km}^{2}$ and $13,606 \mathrm{~km}^{2}$, respectively. This is because the decision objectives under S1 and S2 were inconsistent, which respectively aim to achieve the maximum system benefits and minimum irrigation water volumes of the agricultural system. The above results could provide decision-making references in a single hierarchy. However, the SLP method could not solve the contradictions among two or more hierarchies. Besides, the optimization results might be affected by different leadership-followership relations among multiple hierarchies. For example, the cultivated area of vegetables under S4 would increase by $5.7 \%$ and decrease by $4.3 \%$ compared to S2 and S1 because of the decision objectives which took the conflicts between water and food into consideration. In detail, the water sector (i.e. the UDM sector) could guide decisions for the agricultural sector (i.e. the LDM sector), and the agricultural sector could make corresponding feedback mechanisms to adjust its planting structure, and then finally achieve the maximum satisfaction between the UDM and LDM. Comparably, the results also implied that the cultivated area of vegetables would increase from $15,064 \mathrm{~km}^{2}$ (S3) to $15,439 \mathrm{~km}^{2}$ (S5) and decrease from $15,751 \mathrm{~km}^{2}$ (S4) to $15,439 \mathrm{~km}^{2}$ (S5). This is because S5 aimed at maximizing system benefits of the agricultural sector by the leadership of the water and energy sectors. In summary, compared to the SLP method, the MP method would provide effective strategies in addressing different hierarchies by various sectors.

Place Figure 2 here

\subsection{Water irrigation}


The rapid development of agriculture is inseparable from the stable supply of water resources, therefore the research on agricultural irrigation water volume would be urgent. Figure 3 presents the irrigation water volume of different crops under various periods and scenarios. Irrigation water volume would be changed as a result of the adjustments in crop planting pattern. For instance, as displayed in Figure 3b, the irrigation water volume of wheat would decrease from $4,867 \times 10^{6} \mathrm{~m}^{3}$ to $4,824 \times 10^{6} \mathrm{~m}^{3}$ under $\mathrm{S} 1$ during the planning horizon, indicating that the promotion of irrigation efficiency had a passive influence on irrigation water volume. The reason for this was that the improvement of irrigation technology could lead to the reduction of water consumption, as well as the cost in per unit land, even though the cultivated area would be increasing at the same time. In addition, Figure $3 \mathrm{~h}$ presents the irrigation water volume of vegetables under six scenarios in period 1. Results indicated that variations in decision targets would impact the irrigation water volume. For example, irrigation water volume of vegetables would range from $2,001 \times 10^{6} \mathrm{~m}^{3}(\mathrm{~S} 2)$ to $2,213 \times 10^{6} \mathrm{~m}^{3}(\mathrm{~S} 1)$, meaning that taking the maximum system benefit of agricultural as the decision target would have a promoting influence on irrigation water volume. Furthermore, the irrigation water volume of vegetables in S4 would be approximately $5.7 \%$ higher than that in S2. This is because, under S4 (i.e. bi-level target: the maximum satisfactory degree of water-food nexus), the BP would achieve balance between the maximum system benefit and minimum irrigation water of the agricultural system. Moreover, the irrigation water volume of vegetables would decrease $42 \times 10^{6} \mathrm{~m}^{3}$ from S4 to S5 in period 1 . This is because, under S5 (i.e. multi-level target: the maximum satisfactory degree of water-energy-food nexus), the MP would be an effective alternative to achieve the compromise among the maximum system benefits, the minimum irrigation water volume, and the minimum energy consumption of the agricultural system.

Place Figure 3 here

\subsection{Fertilizer consumption}

In the actual planning management of agricultural water and soil resources, the irregular and unregulated consumption of chemical fertilizers could cause a large range of non-point source 
pollution and endanger the water environment. Figure 4 illustrates the fertilizer-utilization alternatives for each crop under different periods and scenarios. For example, the total fertilizer consumption of vegetables would change from $8,061 \times 10^{6} \mathrm{~kg}$ to $8,102 \times 10^{6} \mathrm{~kg}$ during the planning horizon. Results indicated that vegetables would take the priority in using fertilizer owing to the higher system benefits and lower consumption of water resources. In addition, the policy for discharge of pollutants would limit the consumption of chemical fertilizers and increase the purity of chemical fertilizers, which could correspondingly reduce the agricultural non-point source pollution. For instance, in period 1 under $S 1$, fertilizers allocated to cotton and tubers would be $55.5 \times 10^{6} \mathrm{~kg}$ and $81.9 \times 10^{6} \mathrm{~kg}$, respectively; comparatively, in period 1 under $\mathrm{S} 4$, the consumption of fertilizers allocated to cotton and tubers would respectively be $54.3 \times 10^{6}$ $\mathrm{kg}$ and $80.2 \times 10^{6} \mathrm{~kg}$ due to the variation in decision makers' attitudes (i.e. changing from the maximum system benefit to the minimum water resource consumption). Results implied that the consumption of fertilizers in S4 would increase accordingly compared to that in S2 due to the feedback adjustment of the lower-level agricultural sector aiming at maximizing the system benefits.

Place Figure 4 here

\subsection{Pesticide utilization}

Nowadays, as the demand for agricultural products continues to expand, it is indispensable to allocate water and food resources reasonably and use pesticides rationally. Figure 5 presents the proportion and volume of pesticide utilization for different crops in different periods under S1. As shown in Figure 5a, the proportion of pesticide utilization for wheat, corn and vegetables would be relatively higher than other crops in accordance to their cultivated area. For example, over the planning horizon, the volume of pesticide utilization for vegetables would decrease by $2.8 \times 10^{6} \mathrm{~kg}$ because of the increasing efficiency of fertilizer utilization. Results also indicated that relevant departments would regulate relevant policies for discharge of pollutants to strictly control the amount of spraying agricultural pesticides in order to ensure the food safety and create a sustainable environment. Meanwhile, since diff erent scenarios were employed to 
different pesticide-utilization levels by various sectors (i.e. water resources sector, energy sector and agricultural sector), different scenarios would generate various pollutant emissions. For example, the total optimal pesticide-utilization in period 1 would be $126.13 \times 10^{6} \mathrm{~kg}(\mathrm{~S} 1), 119.11$ $\times 10^{6} \mathrm{~kg}(\mathrm{~S} 2)$ and $120.51 \times 10^{6} \mathrm{~kg}(\mathrm{~S} 3)$, respectively. In addition, under S5 (i.e. multi-level target: the maximum satisfactory degree of water-energy-food nexus), the total consumption of spraying pesticide would be about 3.4\% lower than that in S1 and approximately $0.9 \%$ lower than that in S4, respectively.

Place Figure 5 here

\subsection{Total cultivated area}

Figure 6 illustrates the variation tendency of the total cultivated area under the same credibility $(\alpha=1)$ in period 1 and S1, respectively. As revealed in Figure 6a, when $\alpha=1$, the total cultivated area would respectively be $[125.87,133.92] \times 10^{3} \mathrm{~km}^{2}(\mathrm{~S} 1),[118.92,126.06] \times 10^{3} \mathrm{~km}^{2}(\mathrm{~S} 2)$ and $[122.71,130.34] \times 10^{3} \mathrm{~km}^{2}(\mathrm{~S} 4)$, which meant that different decision targets would result in the fluctuation of total cultivated area under various scenarios. Besides, the total cultivated area in period 1would decrease from $[122.71,130.35] \times 10^{3} \mathrm{~km}^{2}$ (S4) to $[121.63,129.07] \times 10^{3} \mathrm{~km}^{2}$ (S5) and increase from $[120.32,127.55] \times 10^{3} \mathrm{~km}^{2}(\mathrm{~S} 3)$ to $[121.63,129.07] \times 10^{3} \mathrm{~km}^{2}(\mathrm{~S} 5)$. This is because, the decision target under S3 could be restricted by the supply of electricity, which would lead to the insufficient energy consumption of agricultural machine. Results also indicated that reducing the consumption of agricultural electricity would achieve the maximum system benefit and the minimum water utilization. As shown in Figure 6c, the total cultivated area under S1 would decrease from $[126.40,134.70] \times 10^{3} \mathrm{~km}^{2}$ to $[124.83,133.45] \times 10^{3} \mathrm{~km}^{2}$ over the planning horizon, illustrating that the restrictions of pesticides and chemical fertilizer consumption would have a negative effect on the total cultivated area.

Place Figure 6 here 


\subsection{System benefits}

Figure 7 presents the system benefits under different scenarios, credibility levels and periods. Results indicated that the system benefits would change from $[300.08,351.54] \times 10^{9} \mathrm{RMB} ¥$ to [532.93, 623.94] $\times 10^{9} \mathrm{RMB} ¥$. As shown in Figure 7a, the highest system benefit would occur in $\mathrm{S} 1$ when $\alpha=0.6$; on the contrary, the lowest system benefit would exist in S2 when $\alpha=1$. Besides, system benefits would gradually increase with time in accordance to the increment of crops yield and the decrement of chemical fertilizer consumption. Figure $7 \mathrm{~d}$ details the changes in system benefits under five scenarios and six periods when $\alpha=1$. For example, the system benefits in period 1 would reduce from $[320.89,375.91] \times 10^{9} \mathrm{RMB} ¥(\mathrm{~S} 1)$ to $[300.08,351.54] \times$ $10^{9} \mathrm{RMB} ¥(\mathrm{~S} 2)$. This is mainly because the decision target of $\mathrm{S} 1$ aimed at achieving the maximum benefit while S2 sought for the minimum water utilization. Moreover, compared to the SLP model (i.e. S1 and S2), the MP model (S5) would also change the system benefits. For example, the system benefits in period 1 would decrease from $[320.89,375.91] \times 10^{9}$ RMB $¥$ (S1) to $[307.87,360.67] \times 10^{9} \mathrm{RMB} ¥(\mathrm{~S} 5)$ and increase from $[300.08,351.54] \times 10^{9} \mathrm{RMB} ¥$ (S2) to [307.87, 360.67] $\times 10^{9} \mathrm{RMB} ¥(\mathrm{~S} 5)$. This is because the decision target of S5 integrated the targets of S1, S2 and S3 into one framework, which would generate the compromised solutions among different hierarchies by water, energy and food sectors.

Place Figure 7 here

\section{Discussion}

\subsection{Accuracy validation}

In this study, the model's results were validated by the local government plan (i.e. $13^{\text {th }}$ Five-Year Plan of Henan Province for Agriculture) (HPPG, 2017) [46]. For instance, the consumption of irrigation water and spraying pesticides would show decreasing trends during the planning period, which would be consistent with the local government plan. Besides, the yield of cotton would keep a decreasing trend while grains, vegetables and fruits would take increasing trends, which 
would be consistent with the actual situation. According to the requirement of " $13^{\text {th }}$ Five-Year Plan of Henan Province for Agriculture", the annual production of grain (i.e. rice, wheat, corn, beans and tubers) would keep at $54.27 \times 10^{9} \mathrm{~kg}$ by 2020 , which is located within the range of $[50.85,57.35] \times 10^{9} \mathrm{~kg}$ from the MIFCP-WEFN model. Moreover, the annual production of oil-bearing crops and vegetables by 2020 would be controlled within $50.10 \times 10^{9} \mathrm{~kg}$ and $62.63 \times$ $10^{9} \mathrm{~kg}$, respectively; comparably, the yields of oil-bearing crops and vegetables would respectively be $[50.52,58.87] \times 10^{9} \mathrm{~kg}$ and $[63.75,70.53] \times 10^{9} \mathrm{~kg}$ under the MIFCP-WEFN model. It is mainly because MIFCP-WEFN would not only take the interest of agricultural sector (i.e. maximized system benefit) into account, but also protect the rights of water and energy sectors (i.e. minimized consumption of water and energy resources). Based on the accuracy validation in a real-world WEFN system of Henan Province, it can be concluded that the MIFCP-WEFN model could apply to the regional-scale as well as other scale WEFN planning issues in terms of the model's complexity and uncertainty. Therefore, effective solutions for planning the WEFN system of Henan Province could be achieved by the MIFCP-WEFN model.

\subsection{Comparison with single level programming (SLP) and bi-level programming (BP)} approaches

Figure $7 \mathrm{~d}$ describes the compared results of system benefits among SLP, BP and MIFCP-WEFN model when $\alpha=1$. Results implied that the system benefit acquired from BP would be in the range of UDM and LDM. For example, as shown in Figure 7d, the system benefit of BP in period 1 would be $[311.43,364.83] \times 10^{9} \mathrm{RMB} ¥$ under S4, [320.89, 375.90] $\times 10^{9} \mathrm{RMB} ¥$ under $\mathrm{S} 1$ and $[300.07,351.54] \times 10^{9} \mathrm{RMB} ¥$ under S2, respectively. This is because the decision-maker in BP focused on the common interests of maximum system benefit and minimum water consumption, while the decision-maker in SLP merely took their individual interest into consideration. Figure $7 \mathrm{~d}$ also presents the compared system benefits from BP and MIFCP-WEFN model . The system benefit in BP (S4) and MIFCP-WEFN (S5) would be $[311.43,364.83] \times 10^{9}$ RMB $¥$ and $[307.87,360.67] \times 10^{9} \mathrm{RMB} ¥$ (S5), respectively. It is mainly because the system benefit in BP merely took water resources and agricultural sectors into account, which was concentrated on the counterpoise of water consumption and economic performance. Nevertheless, the MIFCP-WEFN model aimed at exploring the most appropriate tradeoffs among water 
conservation, energy consumption and economic performance. In other words, in the MIFCP-WEFN model, the water-resource sector as an up-level decision maker would lead the energy sector (the middle-level decision maker) and agricultural sector (the low-level decision maker) to make some decisions, meanwhile, the energy and agricultural sectors would make corresponding adjustments and feedbacks to the water-resources sector. Thus, the MIFCP-WEFN model would be superior to the SLP and BP approaches in dealing with multiple hierarchy issues existing in MIFCP-WEFN model.

\section{Conclusions}

In this study, a MIFCP method has been exploited by merging with MP, FCP and IPP into one framework. MIFCP is not only effective for dealing with uncertainties expressed as interval parameters and fuzzy sets but also effective for handling conflicts and hierarchical relationships among multiple decision departments. Based on the MIFCP approach, a MIFCP-WEFN model has been formulated for planning the WEFN system of Henan Province. Solutions of three different decision targets in various hierarchy levels, five scenarios with different decision makers' objectives and five $\alpha$ levels corresponding to different necessity degrees have been examined. Several findings in association with various planting structures, water resources demand, energy consumption, fertilizer and pesticide utilizations and system benefits have been achieved.

Based on the MIFCP-WEFN model, results indicated that a) the future total irrigation-water would decrease by $1.5 \%$ from years 2020 to 2025 ; b) the total cultivated area would change by $1.9 \%$ owing to the variation of fertilizer and pesticide change. Compared to SLP and BP approaches, the MIFCP-WEFN model would help decision-makers identify the optimal agricultural water resourceses management schemes by means of the leadership of water resources managers as well as the feedback of two diverse followers (i.e. energy managers and agricultural managers), which would avoid the subjective opinions from only one type of decision-makers and make tradeoffs from diverse decision-makers or managers.

Although the MIFCP-WEFN model could deal with contradictions among various 
leadership-followership relations under multiple levels and multiple uncertainties. However, in real-world WEFN management problems, the flow of natural surface water may be affected by a variety of factors from climate, topographic and other aspects, thus the stochastic programming shall be adopted in response to such problems. Besides, in this study, only one water resource (i.e. surface water) were considered, and the other water resources such as groundwater, diverted water and reclaimed water shall be further considered in order to improve the applicability of the MIFCP-WEFN model.

\section{Acknowledgements}

This research was supported by the National Natural Science Foundation of China (51909239), the Key Research Project of Henan Higher Education Institution (20A570001), and the Postdoctoral Foundation of Henan Province (1901008). The authors are grateful to the editors and the anonymous reviewers for their insightful comments and suggestions. 


\section{References}

[1] Wostl CP. Governance of the water-energy-food security nexus: a multi-level coordination challenge. Environmental Science and Policy 2019;92:356-367.

[2] Steffen W, Richardson K, Rockström J, Cornell SE, Fetzer I, Bennett EM, Biggs R, Carpenter SR, Vries WD, Wit CA, Folke C, Gerten D, Heinke J, Mace GM, Persson LM, Ramanathan V, Reyers B, Sörlin S. Planetary boundaries: guiding human development on a changing planet. Science 2015;347(6223):1259855.

[3] Liu J, Mooney H, Hull V, Davis SJ, Gaskell J, Hertel T, Lubchenco J, Seto KC, Gleick P, Kremen C, Li SX. Systems integration for global sustainability. Science 2015;347(6225):1258832.

[4] Shang YZ, Hei PF, Lu SB, Shang L, Li XF, Wei YP, Jia DD, Jiang D, Ye YT, Gong JG, Lei XH, Hao MM, Qiu YQ, Liu JH, Wang H. China's energy-water nexus: assessing water conservation synergies of the total coal consumption cap strategy until 2050. Applied Energy 2018;210:643-660.

[5] Das B, Singh A, Panda SN, Yasuda HS. Optimal land and water resources allocation policies for sustainable irrigated agriculture. Land Use Policy 2015;42:527-537.

[6] Yu L, Li YP, Huang GH, Fan YR, Yin S. Planning regional-scale electric power systems under uncertainty: A case study of Jing-Jin-Ji region, China. Applied Energy 2018;212:834-849.

[7] Keskinen M, Guillaume JHA, Kattelus M, Porkka M, Räsänen TA, Varis O. The water-energy-food nexus and the transboundary context: insights from large Asian rivers. Water 2016;8(5):193.

[8] Owen A, Scott K, Barrett J. Identifying critical supply chains and final products: An input-output approach to exploring the energy-water-food nexus. Applied Energy 2018;210:632-642.

[9] Martinez P, Blanco M, Castro-Campos B. The water-energy-food nexus: a fuzzy-cognitive mapping approach to support nexus-compliant policies in Andalusia (Spain). Water 2018;10(5):664.

[10] Wang X, Daigger G, Lee DJ, Liu JX, Ren NQ, Qu JH, Liu G, Butler D. Evolving wastewater infrastructure paradigm to enhance harmony with nature. Science Advance 2018;4(8):q210. 
[11] Perrone D, Murphy J, Hornberger GM. Gaining perspective on the water-energy nexus at the community scale. Environmental Science \& Technology 2011;45(10):4228-4234.

[12] Yu L, Li YP. A flexible-possibilistic stochastic programming method for planning municipal-scale energy system through introducing renewable energies and electric vehicles. Journal of Cleaner Production 2019;207:772-787.

[13] Tsolas SD, Karim MN, Hasan MMF. Optimization of water-energy nexus: a network representation-based graphical approach. Applied Energy 2018;224:230-250.

[14] Liu DD, Guo SL, Liu P, Xiong LH, Zou H, Tian J, Zeng YJ, Shen YJ, Zhang JY. Optimisation of water-energy nexus based on its diagram in cascade reservoir system. Journal of Hydrology 2019;569:347-358.

[15] Salmoral G, Yan XY. Food-energy-water nexus: a life cycle analysis on virtual water and embodied energy in food consumption in the Tamar catchment, UK. Resources, Conservation and Recycling 2018;133:320-330.

[16] Karan E, Asadi S. Quantitative modeling of interconnections associated with sustainable food, energy and water (FEW) systems. Journal of Cleaner Production 2018;200:86-99.

[17] Zhang SD, Taiebat M, Liu Y, Qu S, Liang S, Xu M. Regional water footprints and interregional virtual water transfers in China. Journal of Cleaner Production 2019;228:1401-1412.

[18] Chapagain AK, Hoekstra AY. Virtual Water Trade: A Quantification of Virtual Water Flows Between Nations in Relation to International Crop Trade. Journal of Organic Chemistry 2002;11(7):835-855.

[19] FAOUN (Food \& Agriculture Organization of the United Nations). Energy smart food at FAO: an overview. Rome: FAO 2012.

[20] Souty F, Brunelle T, Dumas P, Dorin B, Ciais P, Crassous R, Müller C, Bondeau A. The nexus land-use model version 1.0, an approach articulating biophysical potentials and economic dynamics to model competition for land-use. Geoscientific Model Development 2012;5(5):1297-1322.

[21] Xydis GA, Liaros S, Botsis K. Energy demand analysis via small scale hydroponic systems in suburban areas: an integrated energy-food nexus solution. Science of the Total Environment 2017;593:610-617.

[22] Georgiou S, Acha S, Shah N, Markides CN. A generic tool for quantifying the energy 
requirements of glasshouse food production. Journal of Cleaner Production 2018;191:384-399.

[23] Bilandzija K, Voca N, Jelcic B, Jurisic V, Matin A, Grubor M, Kricka T. Evaluation of Croatian agricultural solid biomass energy potential. Renewable and Sustainable Energy Reviews 2018;93:225-230.

[24] Venghaus S, Hake JF. Nexus thinking in current EU policies-the interdependencies among food, energy and water resources. Environmental Science and Policy 2018;90:183-192.

[25] Namany S, Al-Ansari T, Govindan R. Optimisation of the energy, water, and food nexus for food security scenarios. Computers and Chemical Engineering 2019;129:106513.

[26] Zhou YL, Chang LC, Uen TS, Guo SL, Xu CY, Chang FJ. Prospect for small-hydropower installation settled upon optimal water allocation: An action to stimulate synergies of water-food-energy nexus. Applied Energy 2019;238:668-682.

[27] Li M, Fu Q, Singh VP, Ji Y, Liu D, Zhang CL, Li TX. An optimal modelling approach for managing agricultural water-energy-food nexus under uncertainty. Science of The Total Environment 2019;651:1416-1434.

[28] Zeng XT, Zhang JL, Yu L, Zhu JX, Li Z, Tang L. A sustainable water-food-energy plan to confront climatic and socioeconomic changes using simulation-optimization approach. Applied Energy 2019;236:743-759.

[29] Hussien WA, Memon FA, Savic DA. A risk-based assessment of the household water-energy-food nexus under the impact of seasonal variability. Journal of Cleaner Production 2018;171:1275-1289.

[30] Li M, Fu Q, Singh VP, Liu D, Li TX. Stochastic multi-objective modeling for optimization of water-food-energy nexus of irrigated agriculture. Advances in Water Resources 2019;127:209-224.

[31] Mercure JF, Paim MA, Bocquillon P, Lindner S, Salas P, Martinelli P, Berchin II, Guerra JBSO, Derani C, Junior CLA, Ribeiro JMP, Knobloch F, Pollitt H, Edwards NR, Holden PB, Foley A, Schaphoff S, Faraco RA, Vinuales JE. System complexity and policy integration challenges: the Brazilian energy-water-food nexus. Renewable and Sustainable Energy Reviews 2019;105:230-243.

[32] Yu L, Li YP, Huang GH. Planning municipal-scale mixed energy system for stimulating renewable energy under multiple uncertainties-the city of Qingdao in Shandong Province, 
China. Energy 2019;166:1120-1133.

[33] Zhang F, Zhang CL, Yan ZH, Guo SS, Wang YZ, Guo P. An interval nonlinear multiobjective programming model with fuzzyinterval credibility constraint for crop monthly water allocation. Agricultural Water Management 2018;209:123-133.

[34] Chen YZ, He L, Guan YL, Lu HW, Li J. Life cycle assessment of greenhouse gas emissions and water-energy optimization for shale gas supply chain planning based on multi-level approach: case study in Barnett, Marcellus, Fayetteville, and Haynesville shales. Energy Conversion and Management 2017;134:382-398.

[35] Khan Z, Linares P, Rutten M, Parkinson S, Johnson N, García-González J. Spatial and temporal synchronization of water and energy systems: Towards a single integrated optimization model for long-term resource planning. Applied Energy 2018;210:499-517.

[36] Emam OE. A fuzzy approach for bi-level integer non-linear programming problem. Applied Mathematics and Computation 2006;172:62-71.

[37] Liu B, Liu YK. Expected value of fuzzy variable and fuzzy expected value models. IEEE Transactions on Fuzzy Systems 2002;10:445-450.

[38] Zeng XT, Li YP, Huang W, Chen X, Bao AM. Two-stage credibility-constrained programming with Hurwicz criterion (TCP-CH) for planning water resources management. Engineering Applications of Artificial Intelligence 2014;35:164-175.

[39] Li M, Guo P, Ren C. Water resources management models based on two-level linear fractional programming method under uncertainty. Journal of Water Resources Planning and Management 2015;141(9):05015001.

[40] Veiseh H, Lotfi T, Allahviranloo T. On general conditions for nestedness of the solution set of fuzzy-interval linear systems. Fuzzy Sets and Systems 2018;331:105-115.

[41] Nie S, Huang CZ, Huang GH, Li YP, Chen JP, Fan YR, Cheng GH. Planning renewable energy in electric power system for sustainable development under uncertainty-A case study of Beijing. Applied Energy 2016;162:772-786.

[42] Yu L, Li YP, Huang GH, Fan YR, Nie S. A copula-based flexible-stochastic programming method for planning regional energy system under multiple uncertainties: A case study of the urban agglomeration of Beijing and Tianjin. Applied Energy 2018;210:60-74.

[43] Lv Y, Huang GH, Li YP, Yang ZF, Liu Y, Cheng GH. Planning regional water resources system using an interval fuzzy bi-level programming method. Journal of Environmental 
Informatics 2010;16:43-56.

[44] Wang KY, Zhang PY. The research on impact factors and characteristic of cultivated land resources use efficiency-take Henan Province, China as a case Study. IERI Procedia 2013;5:2-9.

[45] SBHM (Statistics Bureau of Henan Municipality), 2017. Henan statistical yearbook in 2017. China Statistical Press. Henan, China. Available at: < http://www.ha.stats.gov.cn/hntj/lib/tjnj/2017/indexch.htm $>$.

[46] HPPG (Henan Province People's Government), 2017. The Thirteenth Five-Year Plan of Henan Province for Ecological and Environmental Protection. Henan, China. Available at: < https://www.henan.gov.cn/2017/02-20/248768.html >.

[47] Wang K, Wang SS, Liu L, Yue H, Zhang RQ, Tang XY. Environmental co-benefits of energy efficiency improvement in coal-fired power sector: A case study of Henan Province, China. Applied Energy 2016;184:810-819.

[48] Ma SL, Li RH. Evaluation on Sustainable Food Security in Henan against the Background of Low-Carbon Economy. Agriculture and Agricultural Science Procedia 2010;1:412-416.

[49] Cai W, Lai K, Liu CH, Wei FF, Ma MD, Jia S, Jiang ZG, Lv L. Promoting sustainability of manufacturing industry through the lean energy-saving and emission-reduction strategy. Science of the Total Environment 2019;665:23-32.

[50] Tang YK, Zhang F, Wang SF, Zhang XD, Guo SS, Guo P. A distributed interval nonlinear multi-objective programming approach for optimal irrigation water management in an arid area. Agricultural Water Management 2019;220:13-26.

[51] Dantzig GB. Linear programming under uncertainty. Management Science 1955;1(3-4):197-206.

[52] Cottle RW, Dantzig GB. A generalization of the linear complementarity problem. Journal of Combinatorial Theory 1970;8(1):79-90.

[53] Dantzig GB. Reminiscences about the origins of linear programming. Operations Research Letters 1982;1(2):43-48.

[54] He L, Chen YZ, Li J. A three-level framework for balancing the tradeoffs among the energy, water, and air-emission implications within the life-cycle shale gas supply chains. Resources, Conservation \& Recycling 2018;133:206-228.

[55] WRDHP (Water Resources Department of Henan Province), 2017. Henan Water Resources 
Bulletin. Henan, China.

[56] HBQTS (Henan Bureau of Quality and Technical Supervision), 2014. Agricultural Basic Water Quota of Henan Province. Henan, China. 